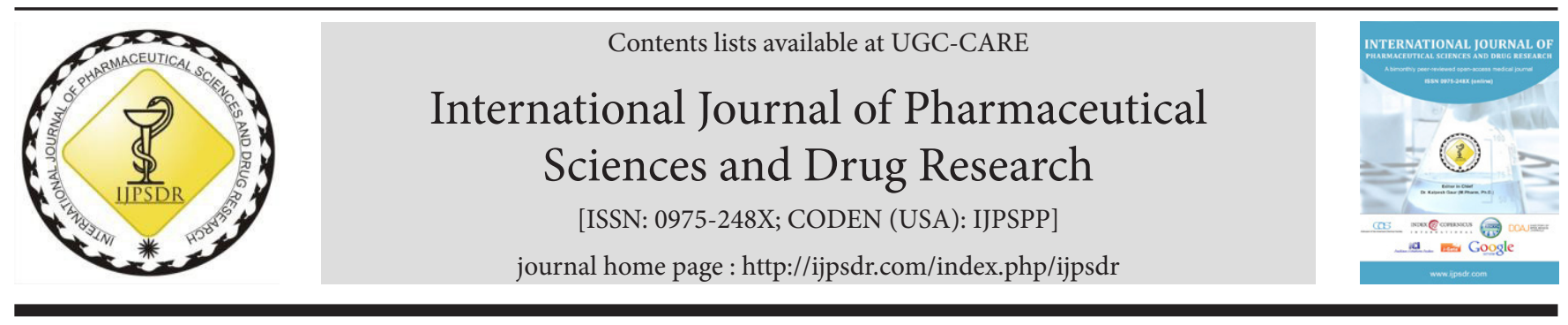

Research Article

\title{
Studies on Comparative Antimicrobial Activities of Aerva lanata and Momordica charantia Leaf Extracts
}

\author{
Nagula Shilpika*, Byagari Teena Keerthana, Banka Srinivas, Gampa Tulja Rani, Ganga Maithili \\ Malla Reddy Pharmacy College, Survey No. 593 and 594, Doolapally Road, Near Forest Academy, Dulapally, Kompally, Secunderabad-500014, \\ Hyderabad, Telangana, India
}

\section{A R T I C L E I N F O \\ Article history: \\ Received: 04 July, 2020 \\ Revised: 21 August, 2020 \\ Accepted: 28 August, 2020 \\ Published: 30 September, 2020 \\ Keywords: \\ Aerva lanata, \\ Antimicrobial activity, \\ Methanolic extract, \\ Momordica charantia, \\ Zone of inhibition. \\ DOI: \\ 10.25004/IJPSDR.2020.120519}

\begin{abstract}
A B S T R A C T
Screening and comparison of antimicrobial action of leaf extract of Aerva lanata and Momordica charantia. Ethyl acetate and methanolic extracts of leaves of plants were screened for antimicrobial activity using the cup plate method and the spread plate method against gram-positive and gram-negative reference organisms (Bacillus subtilis and Escherichia coli). The standard antibacterial agent used for reference is chloramphenicol and the results were calculated as the zone of inhibition. The methanolic extract showed a comparatively broader and better antimicrobial spectrum than ethyl acetate extract in selected plants. Plant extracts showed dose-dependent action, results were similar to the action of the standard chloramphenicol. Extracts of A. lanata and M. charantia demonstrated antimicrobial activity on tested microorganisms. Methanolic extracts showed higher antimicrobial potential than ethyl acetate extract. A. lanata extracts showed a better response than M. charantia extracts in the cup plate method antibacterial activity with $B$. subtilis and E. coli.
\end{abstract}

\section{INTRODUCTION}

In the past decade, many infections, like respiratory, bacterial meningitis, sexually transmitted, and other acquired infections, have acquired resistance to many antimicrobial drugs, especially penicillin, ampicillin, and fluoroquinolones. ${ }^{[1-5]}$ The traditional medicinal plants containing various antimicrobial molecules are used in the alleviation of various infections for their antimicrobial activity and some of the bioactive molecules are used in the market as raw products. Major reasons for antimicrobial resistance are poor patient acceptance and irrational use, resulting in impulsive mutations in the microorganisms. ${ }^{[4-7]}$ Plants have been an essential element of human culture for their fundamental wellbeing. ${ }^{\left[{ }^{8]}\right.} M$. charantia (family Cucurbitaceae) and A. lanata (Amaranthaceae) are used in many parts of Asia, amid its use for skin infections. Tea of these plants is in use for diabetes, to force out intestinal gases, in menstruation, and like antiviral for the treatment of measles and hepatitis. ${ }^{[9-11]}$ In the present study, an effort has been shown to screen the antimicrobial action of extracts of the selected medicinal plants on some human pathogenic bacteria.

\section{Materials AND METhods}

\section{Collection of Plant Materials}

Leaves of both plants were collected from the Siddipet district of Telangana state. A. lanata (Amaranthaceae) was authenticated by Dr. K. Madhav Shetty at Osmania University (Botany Department); (voucher no. 288)

\footnotetext{
"Corresponding Author: Nagula Shilpika

Address: Malla Reddy Pharmacy College, Maisammaguda, Secunderabad, India

Email $₫$ : shilpika047@gmail.com

Relevant conflicts of interest/financial disclosures: The authors declare that the research was conducted in the absence of any commercial or financial relationships that could be construed as a potential conflict of interest.

Copyright (C) 2020 Nagula Shilpika et al. This is an open access article distributed under the terms of the Creative Commons Attribution-NonCommercialShareAlike 4.0 International License which allows others to remix, tweak, and build upon the work non-commercially, as long as the author is credited and the new creations are licensed under the identical terms.
} 
M. charantia (family Cucurbitaceae) was authenticated by Dr. Baba Shankar, Department of Pharmacognosy, School of Pharmacy, Anurag Group of Institutions. Specimen access no.: AG/LCP/MC-155.

\section{Extraction Procedures}

Shade dried plant materials (100 grams of powder of each plant) were extracted by cold maceration method, with $500 \mathrm{~mL}$ of either ethyl acetate or methanol at room temperature for 7 days. The extracts were concentrated by a Rotavapor. Two concentrations of the plant extracts (100 and $200 \mu \mathrm{g} / \mathrm{mL}$ ) were prepared with ethyl acetate and methanol as solvents.

\section{Preliminary Phytochemical Screening}

Phytochemical screening of $M$. charantia and A. lanata leaf extracts with both the above-mentioned solvents were done to identify the occurrence of constituents, like alkaloids, flavonoids, tannin, saponins, carbohydrates, proteins, glycosides, and steroids.

\section{Test Microorganisms and Control Antibiotics}

E. coli (ATCC 25922) and B. subtilis (ATCC 90028) were tested. Chloramphenicol at a dose of $10 \mu \mathrm{g} / \mathrm{mL}$ was used as a standard antibacterial drug.

\section{Antimicrobial Assay}

\section{Cup Plate Method}

Nutrient agar medium is used for the antimicrobial assay. The nutrient agar is prepared by dissolving 20 grams of nutrient agar in $200 \mathrm{~mL}$ of distilled water. Then, it is autoclaved at $121^{\circ} \mathrm{C}$ for 45 minutes. Sterilized media is allowed to cool and poured into Petri plates. The plates were inoculated with bacteria by streaking. A $6 \mathrm{~mm}$ cork borer was used for making bores. The extracts are dissolved in solvents to form dilutions of 100 and $200 \mu \mathrm{g} / \mathrm{mL}$. Chloramphenicol at a dose of $10 \mu \mathrm{g} / \mathrm{mL}$ is used as standard. The zone of inhibition (ZI) was measured from the diameter of the ZI in $\mathrm{mm}^{[12,13]}$

\section{Pour Plate Method}

Culture plates were and sterilized. A $6 \mathrm{~mm}$ cork borer was used for making bores. Such plates were incubated at $37^{\circ} \mathrm{C}$ for 24 hours. ZI was calculated as mentioned above. The test extracts and the standard were poured into the well using sterile pipettes. ${ }^{[12-15]}$

\section{RESULTS}

\section{Qualitative Analysis of Phytochemicals}

Phytochemical screening results were presented in Table 1. They reveal the presence of alkaloids, phenolics, flavonoids, tannin, carbohydrates, proteins, saponin, glycosides, and steroids (Table 1).

\section{Antimicrobial Activity of Methanolic Extracts}

The methanolic extracts exhibited better activity compared to ethyl acetate extracts. The maximum ZI was shown by methanolic extract against $E$. coli. An increasing dose-response was observed with the methanolic extract of both M. charantia and A. lanata. Both extracts showed similar activity with the methanolic extract. The higher dose showed greater ZI against both E. coli and B. subtilis. The effective antimicrobial doses for methanolic extracts of M. charantia and A. lanata are 100 and $200 \mu \mathrm{g} / \mathrm{mL}$ (Table 2; Fig. 1).

\section{Antimicrobial Activity of Ethyl Acetate Extracts}

A. lanata ethyl acetate extract showed greater activity than $M$. charantia extract. The effective antimicrobial

Table 1: Qualitative phytochemical analysis of leaf extracts of $M$. charantia and A. lanata

\begin{tabular}{llcccc}
\hline & & \multicolumn{2}{c}{ A. Lanata } & \multicolumn{2}{c}{ M. charantia } \\
\cline { 2 - 6 } S. No. & Chemical constituents & Ethyl acetate & Methanol & Ethyl acetate & Methanol \\
\hline 1 & Alkaloids & + & + & + & + \\
2 & Flavonoids & + & + & + & + \\
3 & Tannins & + & + & + & + \\
4 & Carbohydrates & - & + & + & + \\
5 & Proteins & + & - & + & + \\
6 & Saponins & - & + & + & + \\
7 & Glycosides & + & + & + & + \\
8 & Steroids & + & + & + \\
\hline
\end{tabular}

+: Positive; -: Negative

Table 2: ZI of test methanolic extracts and standard drug

\begin{tabular}{lllllll}
\hline & & \multicolumn{2}{l}{$\begin{array}{l}\text { ZI of methanol extract of A. lanata } \\
\text { (in } \mathrm{mm})\end{array}$} & \multicolumn{2}{l}{$\begin{array}{l}\text { ZI of methanol extract of } \\
\text { M. charantia (in mm) }\end{array}$} \\
\cline { 3 - 7 } S. No. & Microorganism & $\begin{array}{l}\text { ZI of chloramphenicol } \\
(10 \mu \mathrm{g} / \mathrm{mL})(\text { in } \mathrm{mm})\end{array}$ & $100 \mu \mathrm{g} / \mathrm{mL}$ & $200 \mu \mathrm{g} / \mathrm{mL}$ & $100 \mu \mathrm{g} / \mathrm{mL}$ & $200 \mu \mathrm{g} / \mathrm{mL}$ \\
\hline 1 & E. coli & 9 & 8.5 & 9.5 & 8.5 & 9.5 \\
2 & B. subtilis & 8 & 8 & 8.5 & 8 & 8.5 \\
\hline
\end{tabular}


Table 3: ZI of test ethyl acetate extracts and standard drug

\begin{tabular}{|c|c|c|c|c|c|c|}
\hline \multirow[b]{2}{*}{ S. No. } & \multirow[b]{2}{*}{ Microorganism } & \multirow{2}{*}{$\begin{array}{l}\text { ZI of chloramphenicol } \\
(10 \mu \mathrm{g} / \mathrm{mL})(\text { in } \mathrm{mm})\end{array}$} & \multicolumn{2}{|c|}{$\begin{array}{l}\text { ZI of ethyl acetate extract of A. lanata } \\
\text { (in } \mathrm{mm} \text { ) }\end{array}$} & \multicolumn{2}{|c|}{$\begin{array}{l}\text { ZI of ethyl acetate extract of } \\
\text { M. charantia (in } \mathrm{mm} \text { ) }\end{array}$} \\
\hline & & & $100 \mu \mathrm{g} / \mathrm{mL}$ & $200 \mu \mathrm{g} / \mathrm{mL}$ & $100 \mu \mathrm{g} / \mathrm{mL}$ & $200 \mu \mathrm{g} / \mathrm{mL}$ \\
\hline 1. & E. coli & 9 & 8 & 9.2 & 8 & 9 \\
\hline 2. & B. subtilis & 8.5 & 7 & 9.5 & 7 & 8.3 \\
\hline
\end{tabular}

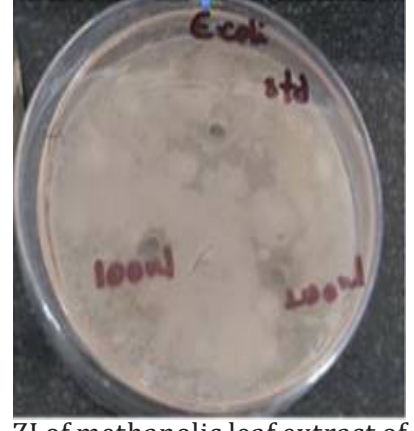

ZI of methanolic leaf extract of A. lanata against E. coli

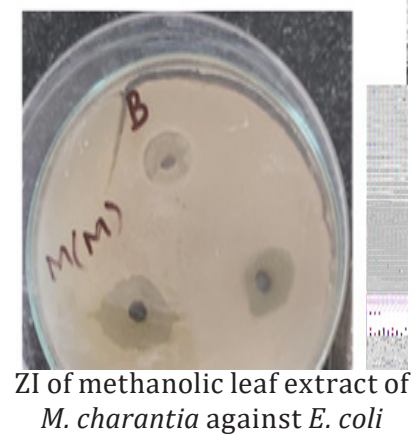

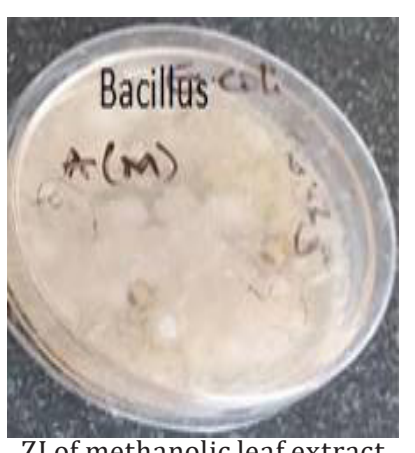

ZI of methanolic leaf extract of $A$. lanata against $B$. subtilis

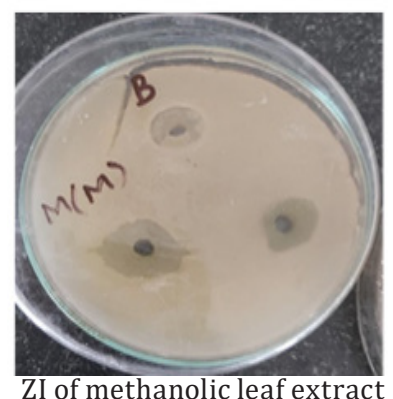

ZI of methanolic leaf extract of $M$. charantia against B. subtilis

Fig. 1: Photographic results showing ZI of test methanolic extracts

doses for ethanolic extracts of $M$. charantia and $A$. lanata are 100 and $200 \mu \mathrm{g} / \mathrm{mL}$. An increasing dose-response was observed and $A$. lanata leaf extract showed a maximum ZI of $9.5 \mathrm{~mm}$ against B. subtilis (Table 3; Fig. 2).

\section{DISCUSSION}

Ethyl acetate extracts of both the plant leaves showed little lesser antimicrobial activity than methanol extracts, better antimicrobial action. This is due to the polarity of active antimicrobial constituents, like alkaloids, glycosides, volatile oils, or tannins, in leaves of $M$. charantia and A. lanata. ${ }^{[16,17]}$ Momordin, alpha- and beta-momorcharin, cucurbitacin B1, and oleanolic acid in $M$. charantia; quercetin and betulin in A. lanata are the active constituents. ${ }^{[18-21]}$ The results of the phytochemical screening states that the selected plant extracts confirmed the presence of all the above-mentioned constituents. It is well proved that the antimicrobial activities of triterpenes are based on the interactions of lipids with the net charge on bacterial membranes. In addition, they pass through bacterial membranes, piercing into the cell and acting on intracellular components vital for antibacterial action. ${ }^{[20]}$

An increasing dose-response was observed with the methanolic extract of both $M$. charantia and $A$. lanata.

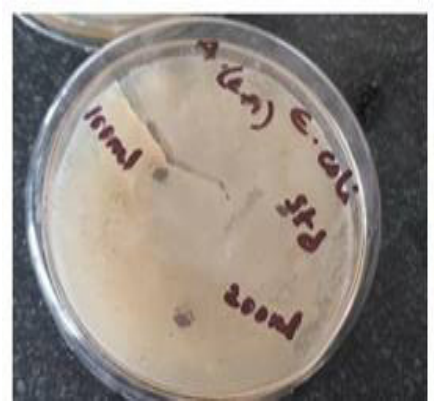

ZI of ethyl acetate leaf extract of $A$. lanata against $E$. coli

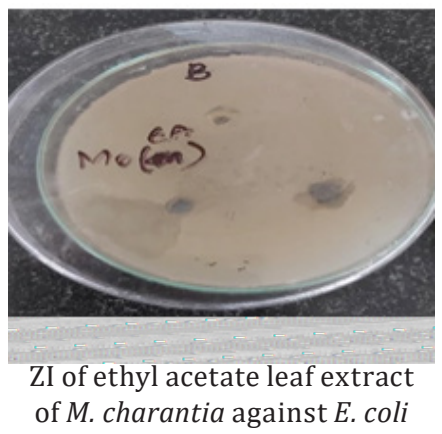

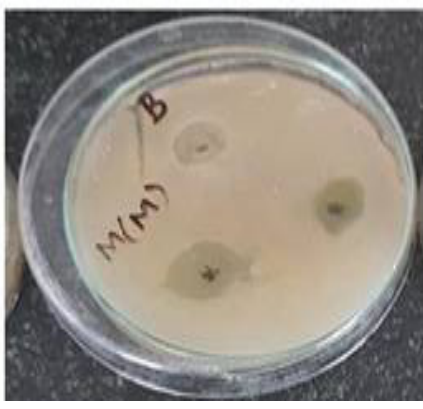

ZI of ethyl acetate leaf extract of $A$. lanata against B. subtilis

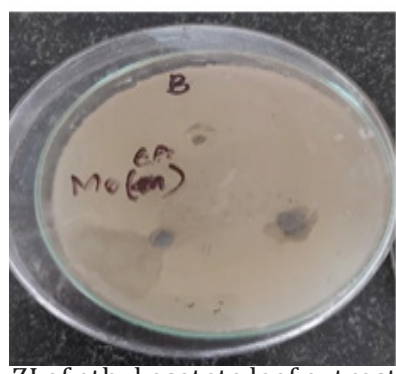

ZI of ethyl acetate leaf extract of $M$. charantia against B. subtilis
Fig. 2: Photographic results showing ZI of test ethyl acetate extracts

Both extracts showed similar activity with the methanolic extract. The higher dose showed greater ZI against both E. coli and B. subtilis. Both the plant extracts showed potent antibacterial activity. Both ethyl acetate and methanolic leaf extract of $A$. lanata showed slightly better activity than $M$. charantia leaf extracts. The cup plate method and the pour plate method postulated similar results. The ZI produced by test extracts was similar to the standard ZI indicating potent antibacterial action of test extracts. Thus, the in vitro antibacterial assays confirm the antibacterial action of methanolic and ethyl acetate extracts of both $M$. charantia and A. lanata.

\section{Conclusion}

This research confirms the antimicrobial potential of the extracts of $M$. charantia and $A$. lanata against bacterial strains that are concerned with opportunistic and hospital-acquired infections. Both the plant extracts showed potent antibacterial activity. Both ethyl acetate and methanolic leaf extract of $A$. lanata showed slightly better activity than $M$. charantia leaf extracts. Additional work is recommended that confirms the in vitro results, isolation of active constituents from crude extracts, and purify the active antimicrobial constituents. Futuristic 
plans also involve conducting toxicity studies for determining their safety.

\section{REFERENCES}

1. Mariswamy Y, Gnaraj WE, Antonisamy JM. Chromatographic fingerprint analysis on flavonoids constituents of the medicinally important plant Aerva lanata L. by HPTLC technique. Asian Pac J Trop Biomed. 2011;1(1):S8-12.

2. Goyal M, Pareek A, Nagori BP, Sasmal D. Aerva lanata: A review on phytochemistry and pharmacological aspects. Pharmacognosy reviews. 2011; 5(10):195.

3. Appapalam ST, Panchamoorthy R. Aerva lanata mediated phytofabrication of silver nanoparticles and evaluation of their antibacterial activity against wound associated bacteria. J Taiwan Inst Chem E. 2017; 78:539-551.

4. Welihinda J, Karunanayake EH, Sheriff MH, Jayasinghe KS. Effect of Momordica charantia on the glucose tolerance in maturity onset diabetes. J. Ethnopharmacol. 1986; 17(3):277-282.

5. Leelaprakash G, Rose JC, Gow tham BM, Javvaji PK, Prasad SA. In vitro antimicrobial and antioxidant activity of Momordica charantia leaves. Pharmacophore. 2011;2(4):244-252.

6. Parkash A, Ng TB, Tso WW. Purification and characterization of charantin, a napin-like ribosome-inactivating peptide from bitter gourd (Momordica charantia) seeds. Int. J. Pept. Res. Ther. 2002;59(5):197-202.

7. Ambasta SS. The useful plants of India. CSIR, New Delhi, India: Publications and Information Directorate; 1986.

8. Okabe H, Miyahara Y, Yamauchi T, Miyahara K, Kawasaki T. Studies on the constituents of Momordica charantia LI Isolation and characterization of momordicosides A and B, glycosides of a pentahydroxy-cucurbitane triterpene. Chem Pharm Bull. 1980;28(9):2753-2762.

9. Ahmed I, Lakhani MS, Gillett M, John A, Raza H. Hypotriglyceridemic and hypocholesterolemic effects of anti-diabetic Momordica charantia (karela) fruit extract in streptozotocin-induced diabetic rats. Diabetes Res. Clin. Pract. 2001;51(3):155-161.
10. Semiz A, Sen A. Antioxidant and chemoprotective properties of Momordica charantia L.(bitter melon) fruit extract. Afr. J. Biotechnol. 2007;6(3).

11. Ahmad N, Hassan MR, Halder H, Bennoor KS. Effect of Momordica charantia (Karolla) extracts on fasting and postprandial serum glucose levels in NIDDM patients. Bangladesh Med Res Counc Bull. 1999;25(1):11-13.

12. Grover JK, Yadav SP. Pharmacological actions and potential uses of Momordica charantia: a review. J. Ethnopharmacol. 2004;93(1): 123-132.

13. Begum S, Ahmed M, Siddiqui BS, Khan A, Saify ZS, Arif M. Triterpenes, a sterol and a monocyclic alcohol from Momordica charantia. Phytochemistry. 1997;44(7):1313-1320.

14. Chang CI, Chen CR, Liao YW, Cheng HL, Chen YC, Chou CH.Cucurbitanetype triterpenoids from the stems of Momordica charantia. J. Nat. Prod;2007;71(8):1327-1330.

15. Akihisa T, Higo N, Tokuda H, Ukiya M, Akazawa H, Tochigi Y, Kimura Y, Suzuki T, Nishino H. Cucurbitane-type triterpenoids from the fruits of Momordica charantia and their cancer chemopreventive effects. J. Nat. Prod. 2007;70(8):1233-1239.

16. Tenaillon O, Skurnik D, Picard B, Denamur E. The population genetics of commensal Escherichia coli. Nat. Rev. Microbiol. 2010;8(3):207-217.

17. Jördening HJ, Winter J, editors. Environmental biotechnology: concepts and applications. John Wiley and Sons; 2005;24.

18. Mba-Jonas A, Culpepper W, Hill T, Cantu V, Loera J, Borders J, et al. A multistate outbreak of human Salmonella agona infections associated with consumption of fresh, whole papayas imported from Mexico-United States, 2011. Clin. Infect. Dis. 2018;66(11): $1756-1761$.

19. Vogt RL, Dippold L. Escherichia coli 0157: H7 outbreak associated with consumption of ground beef, June-July 2002. Public health reports. 2005;120(2):174-178.

20. Bentley R, Meganathan R. Biosynthesis of vitamin K (menaquinone) in bacteria. Microbiol. Rev. 1982;46(3):241.

21. Hudault S, Guignot J, Servin AL. Escherichia coli strains colonising the gastrointestinal tract protect germfree mice against Salmonella typhimurium infection. Gut. $2001 ; 49(1): 47-55$.

HOW TO CITE THIS ARTICLE: Shilpika N, Keerthana BT, Srinivas B, Rani GT, Maithili G. Studies on comparative antimicrobial activities of Aerva lanata and Momordica charantia leaf extracts. Int. J. Pharm. Sci. Drug Res. 2020;12(5):561-564. DOI: 10.25004/IJPSDR.2020.120519 